\title{
LOBO ANTUNES E OS ANTÍPODAS DO AVESSO DO MUNDO
}

Maria Elvira Malaquias de Carvalho Doutoranda em Letras - Estudos Literários

\begin{abstract}
RESUMO
Este artigo visa a designar o avesso do mundo como motivo recorrente no romance $O$ esplendor de Portugal, do escritor português António Lobo Antunes. O texto aponta de que modo o avesso pode ser tomado como eixo das relações dialéticas entre colonizador e colonizado, brancos e negros tal como ocorrem na narrativa.
\end{abstract}

\section{PALAVRAS-CHAVE}

Lobo Antunes, avesso do mundo, colonialismo

Um escritor tenta comunicar à obra que empreende algo de sua consciência, para que possa ser reconhecido por meio de um estilo singular. Albert Camus disse certa vez que cada artista conserva dentro de si uma fonte única, que alimenta durante a vida o que ele é e o que ele diz. Como detectar, no entanto, a frágil expressão de uma singularidade artística, uma vez que um autor se inventa constantemente através de sua obra?

Compreender como se formula e se desenvolve o estilo pessoal de um escritor tão prolífico como António Lobo Antunes não pode ser, portanto, uma tarefa simples. O autor ocupa um lugar de inegável destaque na literatura contemporânea de língua portuguesa. Os inúmeros prêmios recebidos, a maior evidência na mídia e o crescimento de sua fortuna crítica no Brasil, nos últimos anos, indicam não só que o nome de Lobo Antunes tem sido bem acolhido pelo público acadêmico, mas também que sua obra vem adquirindo um privilegiado espaço para pesquisas avançadas em nosso país.

Desde os primeiros livros do romancista português, observavam-se determinadas recorrências temáticas ou ideológicas que afinal puderam apontar ao leitor um projeto literário em desenvolvimento. Uma abordagem comparativa dos romances de Antunes permite notar uma cuidadosa sistematicidade no emprego da palavra “avesso” e expressões correlatas. De difícil conceitualização, o termo abriga inúmeros sentidos e performances em sua obra. A noção de avesso comporta, por exemplo, um gosto por situações bisonhas e desajeitadas, um 
acúmulo de descrições grotescas e animalizantes dos sujeitos, e ainda uma predileção por ambientes decrépitos e cenários toscos e farsescos.

A apreensão mais imediata do avesso, todavia, está ligada a uma desconcertante sensação de estranheza que os narradores manifestam em relação ao próprio corpo e ao espaço ao seu redor. Assim, as personagens de Lobo Antunes apresentam constantemente um tipo de embriaguez dos sentidos, ou então um certo fastio e uma lassidão de viver que expressam formas profundas de pessimismo.

Muito se fala a respeito do experimentalismo com a linguagem e com a própria estrutura do romance que Lobo Antunes persegue radicalmente. A princípio tão ostensivamente moderna, sua narrativa elabora uma nova tradução do "mundo às avessas", apontado como topos da retórica medieval por Ernst Robert Curtius, em sua célebre Literatura européia e Idade Média Latina. A maneira pela qual o escritor se apropriou desse topos evidencia não só que a originalidade de sua escrita é feita de continuidades e rupturas com a tradição literária ocidental, mas ainda que o persistente interesse de Antunes sobre as particularidades dessa temática lhe rendeu o êxito de ter alcançado inesperadas e sofisticadas formas de interpretação do antigo topos.

A conhecida ideia dos antípodas do avesso do mundo - os adjetivos aqui podem variar, diz-se também mundo revirado, invertido, às avessas, etc. - perde-se nas origens da sátira e da paródia na Grécia Antiga, estendendo-se, a partir de glosas e retomadas, à Idade Média. Mikhail Bakhtin, em suas formulações sobre o carnaval medieval, associou o "mundo às avessas” aos procedimentos e atitudes que encontrou na chamada sátira menipeia, um determinado gênero textual que seria a matriz literária de Rabelais e Dostoiévski, e que teria tido grande importância para a evolução do romance europeu moderno.

De emprego universal [eu trocaria o "universal” por “amplo”] na literatura, o mencionado topos do “mundo às avessas” adquiriu, em Lobo Antunes, um significado local e pragmaticamente relacionado a importantes eventos da história recente de Portugal: a guerra colonial africana, os movimentos de independência das ex-colônias e a queda da ditadura salazarista. Transformado em leitmotiv na extensa obra do autor português, o avesso - ou, mais especificamente, a ideia do avesso do mundo - ganha plena relevância em $O$ esplendor de Portugal.

O livro questiona os lugares fixos do colonizador e do colonizado ao perturbar a concepção binária de mando e submissão entre brancos e negros, seja na esfera política, seja no âmbito doméstico, íntimo e afetivo. As relações entre a ex-metrópole e a ex-colônia são compreendidas como reversibilidade de papéis e não como mera imposição de poder de 
Portugal em direção à África. O épico título do romance é o primeiro indicador de vários avessos, já que $O$ esplendor nada mais é que uma visão deprimente da descolonização africana.

Ao mesmo tempo que satiriza o declínio da elite colonial angolana, representada pela família da fazendeira Isilda, a narrativa investe polemicamente contra uma ideia mítica da nação, forjada a partir da expansão ultramarina portuguesa dos séculos 15 e 16 . O protagonismo de Isilda chama a atenção nesse romance que trata de guerra e de educação feminina. Mesmo dentro da aristocracia colonial, a trajetória da fazendeira se desvia tanto da ideologia e da tarefa do colonizador quanto da imagem típica do feminino. Caracterizada por um corpo monstruoso, amálgama grotesco de um vestido branco e um pano do Congo, Isilda simboliza todas as incoerências de uma "raça detestável e híbrida,"1 constituída por brancos menosprezados em Lisboa porque não passam de algo intermediário entre o europeu e o africano.

Na perspectiva pós-colonialista em destaque na obra, é interessante perceber de que modo o avesso do mundo reavalia uma determinada concepção geográfica que o Ocidente feudal e teocêntrico mantinha em relação aos povos estrangeiros. Espaço onde habitavam os antípodas, segundo as superstições da epistemologia medieval, o avesso era também a periferia do mundo, como nos lembra José Gil, em seu livro Monstros. ${ }^{2}$ O filósofo refere-se à antiga crença dos europeus na existência de raças fabulosas que se encontrariam nos confins da Terra, sobretudo na Índia e na África.

A iconografia medieval representava os antípodas em traços monstruosos e demoníacos. Resgatando aspectos da visão de Santo Agostinho sobre tais raças maravilhosas do Oriente e comentando alguns trechos da Cidade de Deus, Gil examina determinados impasses do religioso acerca do problema do avesso do mundo. As diferenças dos antípodas em relação “ao corpo normal, cristão, ocidental onde se aloja a alma humana”3 não se adequavam aos dogmas da Igreja. Perturbada com as anomalias que via nas figuras dos antípodas, a mentalidade cristã europeia teria sido exposta a perigosos questionamentos, inconvenientes para a Igreja, sobre a pertença desses seres fabulosos à obra de Deus.

Por mais obscuro e estranho que fosse, o avesso do mundo podia oferecer ao homem medieval uma possibilidade de conforto que, em última instância, assegurava a ordem de um

\footnotetext{
${ }^{1}$ ANTUNES O esplendor de Portugal, p. 244.

${ }^{2}$ GIL. Monstros.

${ }^{3}$ GIL. Monstros, p. 34.
} 
pensamento fundamentalmente eurocêntrico. Isso porque os antípodas, tomados dentro de um sistema de oposições, também proporcionavam uma maneira de relegar ao domínio da alteridade tudo o que fosse monstruoso, horrível e imperfeito na existência humana. Nas figuras grotescas que povoam a mentalidade cristã medieval, de acordo com Gil, o Ocidente pode extrair o necessário para se reconhecer a si mesmo, “não numa imagem invertida, mas a partir desse avesso que dá estabilidade e sentido a todas as imagens familiares e reconfortantes de si mesmo que ele constrói”. ${ }^{4}$

Contemporaneamente glosado por Lobo Antunes, o avesso do mundo é agora incapaz de remeter o indivíduo de volta à segurança de seu lar. $O$ esplendor de Portugal frustra as expectativas de um suposto lugar adequado ou confortável para o colonizador e o colonizado, tão indistintas se tornam essas duas categorias. Na girândola de inversões e reversões que envolve a troca de lugar entre o branco e o negro, não há nada mais precário que a determinação do sentimento de pertença das personagens, seja em relação à família, seja em relação à nação.

O romance tampouco se atém à lógica da carnavalização, que, originalmente, segundo Bakhtin, tinha o valor da festa da praça pública e do congraçamento entre as pessoas. Muito ao contrário desse espírito positivo da época do humanismo em que o carnaval nasceu, o texto discute não a convivência pacífica dos opostos, mas as contrapartidas perversas de um compósito social visto ceticamente através de uma dialética negativa.

Lobo Antunes atribuiu ao antigo topos um acento crítico e atual ao transformar a suposta rigidez de uma convenção literária oriunda da retórica clássica em um vívido painel da experiência colonial e das antinomias que sustentaram a relação com a alteridade, tanto em Portugal como na África. Dentre os vários sentidos que a noção de avesso toma na obra de Antunes, é o conflito das paixões humanas o elemento que mais interessa no exame de suas personagens. Porque o avesso é, afinal, psicomaquia: a luta de si contra si própria que Isilda tão bem encena.

\footnotetext{
${ }^{4}$ GIL. Monstros, p. 59.
} 


\section{ABSTRACT}

The objective of this article is to describe the reverse of the world as the recurrent motive of the novel $O$ esplendor de Portugal, by the Portuguese author António Lobo Antunes. The text points out the way in which the reverse can be taken as the axis of the dialectal relationships between the colonizer and the colonized, the whites and the blacks, as portrayed in the novel.

\section{KEYWORDS}

Lobo Antunes, topos of the "world upsidedown”, colonialism

\section{REFERENNCIAS}

ANTUNES, António Lobo. O esplendor de Portugal. Rio de Janeiro: Rocco, 1999.

BAKHTIN, Mikhail. A cultura popular na Idade Média e no Renascimento: o contexto de François Rabelais. Trad. Yara Frateschi Vieira. São Paulo: Hucitec/Ed. Universidade de Brasília, 1987.

BAKHTIN, Mikhail. Problemas da poética de Dostoiévski. 2. ed. Trad. Paulo Bezerra. Rio de Janeiro: Forense Universitária, 1997.

CURTIUS, Ernst Robert. Literatura européia e idade média latina. Trad. Teodoro Cabral. Rio de Janeiro: Instituto Nacional do Livro, 1957.

GIL, José. Monstros. Lisboa: Quetzal, 1994. 